\title{
Inpatient burden of gastric cancer in the United States
}

\author{
Shantanu Solanki ${ }^{1}$, Raja Chandra Chakinala ${ }^{1}$, Khwaja Fahad $\mathrm{Haq}^{2}$, Muhammad Ali Khan ${ }^{3}$, Alina Kifayat ${ }^{4}$, \\ Katherine Linder ${ }^{5}$, Zubair Khan ${ }^{6}$, Uvesh Mansuri ${ }^{7}$, Khwaja Saad Haq ${ }^{8}$, Christopher Nabors ${ }^{4}$, Wilbert S. Aronow \\ ${ }^{1}$ Hospitalist Department, Guthrie Robert Packer Hospital, Sayre, PA, USA; ${ }^{2}$ Division of Gastroenterology, Henry Ford Hospital, Detroit, MI, USA; \\ ${ }^{3}$ Division of Gastroenterology, University of Tennessee Health Science Center, Memphis, TN, USA; ${ }^{4}$ Department of Medicine, New York Medical \\ College at Westchester Medical Center, Valhalla, NY, USA; 'Division of Hematology-Oncology, Baylor College of Medicine, Houston, TX, USA; \\ ${ }^{6}$ Department of Medicine, University of Toledo Medical Center, Toledo, OH, USA; ${ }^{7}$ Department of Medicine, MedStar Health, Baltimore, MD, \\ USA; ${ }^{8}$ Department of Medicine, Kingsbrook Jewish Medical Center, Brooklyn, NY, USA; ${ }^{9}$ Department of Cardiology, New York Medical College at \\ Westchester Medical Center, Valhalla, NY, USA \\ Contributions: (I) Conception and design: S Solanki, RC Chakinala, KF Haq; (II) Administrative support: S Solanki, KF Haq, WS Aronow; (III) \\ Provision of study materials or patients: S Solanki; (IV) Collection and assembly of data: S Solanki, MA Khan, U Mansuri; (V) Data analysis and \\ interpretation: S Solanki, KF Haq, KS Haq, RC Chakinala, A Kifayat, K Linder, Z Khan; (VI) Manuscript writing: All authors; (VII) Final approval \\ of manuscript: All authors. \\ Correspondence to: Shantanu Solanki, MD, MPH. 211B W Lockhart Street, Sayre, PA 18840, USA. Email: shan4788@gmail.com.
}

\begin{abstract}
Background: Gastric cancer is associated with significant morbidity and mortality. Over one-half of patients have advanced disease at the time of presentation, leading to a significant burden on the healthcare system. Limited epidemiological data exists on national inpatient hospitalization trends. The aim of this study is to determine the inpatient burden of gastric cancer in the United States.

Methods: We analyzed the Nationwide Inpatient Sample (NIS) database for all subjects with the diagnosis of malignant neoplasm of the stomach (ICD-9 code 151.x) as primary diagnosis during the period from 2001-2011. NIS is the largest all-payer inpatient care database in the U.S. Statistical significance of variation in the number of hospitalizations, patient demographics, and comorbidity measures was determined using Cochran-Armitage trend test.
\end{abstract}

Results: From 2001 to 2011, the number of hospitalizations with the diagnosis of malignant neoplasm of the stomach ranged between 22,430 and 25,371, however, the trend was not significant. Men were always more affected than women with no significant change in overall proportion $(\mathrm{P}<0.0001)$. Overall, in-hospital mortality decreased from $11.19 \%$ in 2001 to $6.47 \%$ in $2011(\mathrm{P}<0.0001)$. However, average cost of care per hospitalization increased from $\$ 21,710$ in 2001 to $\$ 24,706$ in 2011 (adjusted for inflation, $\mathrm{P}<0.0001$ ).

Conclusions: The total number of hospitalizations remained relatively stable throughout the study period with higher proportion of men affected every year. Although in-hospital mortality in patients with the diagnosis of gastric cancer decreased over the study period, there was a significant rise in the cost of care.

Keywords: Gastric cancer; mortality; cost; survival

Submitted Sep 02, 2019. Accepted for publication Nov 06, 2019.

doi: $10.21037 /$ atm.2019.11.54

View this article at: http://dx.doi.org/10.21037/atm.2019.11.54

\section{Introduction}

Gastric cancer was the leading cause of cancer death in the United States (U.S.) until the late 1930s (1). Since then, the proportion of gastric cancer has decreased substantially in the U.S. and is now the fifteenth leading cause of cancer death (2). In the U.S., annual age-standardized mortality from gastric cancer was estimated to be 3.00 per 100,000 men and 1.46 per 100,000 women between 2000 to 2004 by Ferro and colleagues (3). These rates decreased to 2.55 per 100,000 men and 1.28 per 100,000 women from 2005 to 2009 in that study, showing a clear decrease in the 
mortality rates in the U.S. However, survival remains poor and $65 \%$ of the gastric cancers are discovered at an advanced stage $(4,5)$.

Over one-half of patients have advanced disease at the time of presentation, leading to a significant burden on the healthcare system (6). The total cost of gastric cancer was estimated to be $\$ 1.82$ billion in 2010 by Mariotto et al. at the National Cancer Institute in the U.S. (7). This study noted that the total cost of care of gastric cancer in the U.S. is projected to be $\$ 2.31$ billion in 2020 . However, it was performed on a population based registry and therefore was not a strictly inpatient study. Knopf et al. estimated mean monthly costs for gastric cancer patients to be $\$ 10,653$ between 2007 and 2009 (8). Again, this study was done using IMS LifeLink Health Plan Claims Database, which includes both inpatient and outpatient diagnoses (9).

An accurate understanding of trends in gastric cancer related hospitalizations is necessary for future healthcare planning considering the enormous rise in cost care anticipated by year 2020. A national study which identifies vulnerable groups may permit more effective future reductions in health care disparities than a single center and/or multi-center studies $(10,11)$. Thus, we designed our study using a national inpatient database.

The Nationwide Inpatient Sample (NIS), designed by Agency for Healthcare Research and Quality (AHRQ), is the largest all-payer inpatient database in the U.S. Data are compiled yearly and contain discharge information from over 1,200 hospitals located across 45 states in the U.S. The NIS was designed to approximate a $20 \%$ stratified sample of community hospitals in the country and provides sampling weights to calculate national estimates (12). The NIS contains information included in a typical discharge summary, with safeguards in place to protect the privacy of individual patients, physicians, and hospitals. Each individual hospitalization is de-identified and maintained in the NIS as a unique entry with one primary discharge diagnosis and approximately twenty-four secondary diagnoses during that hospitalization (13). Each entry also carries information on demographic details, insurance status, comorbidities, primary/secondary procedures, hospitalization outcomes, length of stay, and cost of care. The internal validity of the database is guaranteed by annual data quality assessments of the sample. Moreover, comparisons with data sources like the American Hospital Association (AHA) Annual Survey of Hospitals, National Hospital Discharge Survey from the National Center for Health Statistics, and Medicare Provider and Analysis
Review (MedPAR) inpatient data from the Centers for Medicare and Medicaid Services strengthen the external validity of the sample $(14,15)$.

\section{Methods}

\section{Study design}

This is a retrospective cohort study in which we queried the NIS database from year 2001 to 2011 to identify all the hospitalizations with gastric cancer. We extracted data regarding all the hospitalizations from 2001 to 2011 with primary diagnosis of gastric cancer, which in turn was identified with International Classification of Diseases, 9th Revision, Clinical Modification, ICD-9 code 151.x. Patients with age less than 18 years were excluded, as were hospitalizations with missing information related to age, gender, admission/discharge date, and in-hospital mortality status and demographics and comorbidities as seen in other NIS based studies $(11,16)$. To calculate estimated cost of hospitalizations, NIS data were merged with cost-to-charge ratio (CCR) files available from the Healthcare Cost and Utilization Project. We estimated the cost of each inpatient stay by multiplying the total hospital charge with CCR. This study was exempted from ethics approval because we did not use personally identifiable information (PII).

\section{Variables and statistical analysis}

SAS 9.4 (SAS Institute Inc., Cary, North Carolina, USA) was utilized for complex statistical analyses. Since NIS represents a $20 \%$ stratified random sample of U.S. hospitals, analyses were performed using hospital-level discharge weights provided by the NIS, to obtain national estimates of hospitalizations. Gastric cancer-related hospitalizations per million U.S. population were calculated by dividing the number of such hospitalizations in each year by U.S. census population greater than 18 years age for that year. Gastric cancer hospitalizations were also calculated in subgroups of age (18-34, 35-49, 50-64, 65-79, and $\geq 80$ years), gender, race (White, Black, Hispanic, Asian or Pacific Islander, Native American, and others), insurance status (Medicare/ Medicaid, private insurance, self-pay/other), hospital location in different U.S. regions (Northeast, Midwest, South, West), and teaching status of the hospital. According to AHRQ, a hospital is considered to be a teaching hospital if it is: (I) an AMA-approved residency program,; (II) a member of the Council of Teaching Hospitals; or (III) a 
hospital with a full-time intern and resident-to-bed (IRB) ratio more than 0.25 (17). The Cochrane-Armitage trend test was used to calculate trends in categorical variables (18). The Wilcoxon rank sum test was used to assess continuous variables (19).

\section{Results}

\section{Demographics}

A total of 264,686 hospitalizations for gastric cancer (as primary diagnosis) were identified in the U.S. population from 2001 to 2011, with 23,880 hospitalizations in 2001 and 23,281 in $2011(\mathrm{P}=0.3)$. Patient characteristics are described in Table 1. Gastric cancer patients were predominantly White (49.0\%) and between 65 and 79 years of age (38.6\%) (Figure 1). There were more hospitalizations in males $(62.7 \%)$ than females $(37.2 \%)$. The gender ratio was stable throughout the study period. Medicare/Medicaid was the primary payer for $63.3 \%$ of gastric cancer hospitalizations. The majority of gastric cancer hospitalizations were reported in the South $(34.3 \%)$, followed by the Northeast (24.4\%), West (21.3\%), and Midwest (20.0\%) (Table 1). However, the incidence of gastric cancer hospitalizations was highest in the Northeast, accounting for 84.7 hospitalizations per 100,000 hospitalizations when compared to 61.0 per 100,000 hospitalizations in the South.

\section{Trends in hospitalizations}

The gastric cancer hospitalization rate remained relatively stable between 2001 and 2011 ( $\mathrm{P}=0.3$ ) (Table 2). The magnitude of rise in gastric cancer-related hospitalizations was higher in 50-64 age group (relative increase 36.9\%, $\mathrm{P}<0.0001$ ) than $18-34$ age group (relative increase $20 \%$, $\mathrm{P}<0.0001$ ) (Table 2). Age group 35-49 showed $12.5 \%$ decline in the hospitalization rate between 2001 and $2011(\mathrm{P}<0.0001)$. Women accounted for $38.8 \%$ of total gastric cancer hospitalizations in 2001 and $36.9 \%$ of total gastric cancer hospitalizations in 2011. The gastric cancer hospitalization rate was higher in White than other racial groups throughout the study. All racial groups showed an increase in the rates between 2001 and $2011(\mathrm{P}<0.0001)$ (Table 2).

\section{All-cause in-hospital mortality}

The rate of in-hospital mortality in gastric cancer showed a significant decrease from $11.2 \%$ in 2001 to $6.5 \%$ in 2011 $(\mathrm{P}<0.0001)$ (Table 3). Across the age groups, the mortality rate was highest in $\geq 80$ years age group at $10.6 \%$. The average mortality rates between men and women were similar during the study period ( $9.0 \%$ vs. $8.8 \%$, respectively) $(\mathrm{P}=0.0141)$ (Table 3). The highest mortality rate $(10.4 \%)$ was among Black $(\mathrm{P}<0.0001)$ (Figure 2) and lowest in the Native American population (8.0\%). Mortality was highest in Northeast (10.8\%) and lowest in the West (7.8\%). It was higher in hospitals in the rural area (10.6\%) than urban teaching hospital (7.9\%) (Table 1).

\section{Cost of care}

After adjustment for inflation, the mean cost of hospitalizations with a gastric cancer diagnosis increased from $\$ 21,710$ in 2001 to $\$ 24,706$ in $2011(\mathrm{P}<0.0001)$ (Table 4). The estimated annual cost of managing patients with gastric cancer was $\$ 518$ million in 2001 and $\$ 575$ million in 2011. The mean cost of care was lowest if gastric cancer-related hospitalization was in the Midwest $(\$ 4,819)$ and rural hospitals $(\$ 1,855)$. It was highest in the South $(\$ 8,245)$ and urban teaching hospitals $(\$ 13,233)$ (Table 4).

\section{Comorbidities associated with hospitalizations}

AHRQ comorbidities most commonly associated with gastric cancer-related hospitalizations were hypertension (40.3\%), anemia (23.8\%), and diabetes without complications (15.5\%) (Table 1).

\section{Predictors of mortality}

After adjusting for confounding factors, Black race was found to be at have a stronger association with risk of mortality in gastric cancer-related hospitalizations as compared to White (OR 1.3; 95\% CI: 1.2 to $1.4 ; \mathrm{P}<0.0001$ ). Alcohol abuse and obesity were also significantly associated with increased the risk of mortality (Table 5).

\section{Discussion}

To our knowledge, this is the second retrospective study determining the inpatient burden of gastric cancer in the U.S. Liu et al. conducted a similar study using NIS database in 2018 (20). All other studies have reported findings from population-based cancer registries like Surveillance, Epidemiology, and End Results (SEER), United States 
Table 1 Baseline characteristics of the gastric cancer hospitalizations

\begin{tabular}{|c|c|c|c|c|c|c|c|c|c|c|c|c|c|}
\hline Variable & 2001 & 2002 & 2003 & 2004 & 2005 & 2006 & 2007 & 2008 & 2009 & 2010 & 2011 & Overall & $P$ value \\
\hline Number of hospitalizations (n) & 23,880 & 23,955 & 24,950 & 23,590 & 24,728 & 22,430 & 25,371 & 24,415 & 22,793 & 25,294 & 23,281 & 264,686 & 0.3 \\
\hline \multicolumn{14}{|l|}{ Age in years $(\%)$} \\
\hline $35-49$ & 10.4 & 10.5 & 10.6 & 11.1 & 10.9 & 9.1 & 11.0 & 10.0 & 10.7 & 11.1 & 9.1 & 10.4 & 0.0068 \\
\hline $50-64$ & 23.3 & 25.3 & 25.1 & 27.5 & 28.1 & 28.2 & 30.0 & 28.7 & 31.1 & 32.0 & 31.9 & 28.3 & $<0.0001$ \\
\hline$\geq 80$ & 22.5 & 22.9 & 22.4 & 22.1 & 21.1 & 21.9 & 19.0 & 22.2 & 18.9 & 18.2 & 18.4 & 20.9 & $<0.0001$ \\
\hline \multicolumn{14}{|l|}{ Gender (\%) } \\
\hline Male & 61.2 & 62.1 & 62.3 & 62.5 & 63.1 & 61.4 & 63.6 & 64.1 & 62.6 & 64.0 & 63.0 & 62.7 & $<0.0001$ \\
\hline Female & 38.8 & 37.9 & 37.6 & 37.4 & 36.7 & 38.5 & 36.3 & 35.8 & 37.3 & 36.0 & 36.9 & 37.2 & \\
\hline Black & 10.5 & 10.6 & 11.2 & 12.1 & 9.2 & 10.8 & 11.2 & 12.4 & 11.6 & 15.5 & 14.8 & 11.8 & $<0.0001$ \\
\hline Hispanic & 8.9 & 8.6 & 10.9 & 10.4 & 10.9 & 11.5 & 10.7 & 9.9 & 11.8 & 14.9 & 13.5 & 11.1 & $<0.0001$ \\
\hline Asian or Pacific Islander & 4.1 & 6.1 & 5.9 & 5.3 & 5.5 & 5.6 & 6.8 & 6.4 & 7.7 & 5.9 & 5.2 & 5.9 & $<0.0001$ \\
\hline Native American & 0.2 & 0.3 & 0.1 & 0.3 & 0.2 & 0.4 & 0.8 & 0.3 & 0.6 & 0.9 & 0.3 & 0.4 & $<0.0001$ \\
\hline Others & 2.1 & 2.4 & 2.2 & 1.7 & 2.6 & 2.3 & 2.7 & 2.7 & 4.0 & 3.3 & 3.8 & 2.7 & $<0.0001$ \\
\hline \multicolumn{14}{|l|}{ Region (\%) } \\
\hline Northeast & 26.0 & 23.9 & 23.2 & 26.5 & 24.9 & 22.3 & 28.6 & 24.2 & 21.7 & 24.5 & 22.5 & 24.4 & $<0.0001$ \\
\hline Midwest & 22.0 & 20.6 & 19.3 & 20.1 & 21.7 & 19.6 & 17.6 & 17.7 & 21.2 & 21.6 & 19.2 & 20.0 & $<0.0001$ \\
\hline \multicolumn{14}{|l|}{ Median household income (\%) } \\
\hline Quartile 1 & 6.4 & 4.1 & 25.4 & 27.3 & 25.2 & 26.9 & 26.4 & 26.6 & 25.7 & 28.0 & 26.7 & 22.6 & $<0.0001$ \\
\hline Quartile 2 & 20.4 & 20.0 & 26.3 & 26.0 & 23.9 & 24.0 & 22.8 & 24.6 & 24.3 & 23.9 & 23.5 & 23.6 & $<0.0001$ \\
\hline Quartile 3 & 27.3 & 22.6 & 24.7 & 20.9 & 25.9 & 24.3 & 22.6 & 22.5 & 23.0 & 22.6 & 24.5 & 23.7 & 0.0016 \\
\hline Quartile 4 & 44.8 & 51.1 & 21.5 & 23.4 & 22.6 & 22.9 & 25.3 & 23.5 & 23.4 & 22.5 & 23.9 & 27.7 & $<0.0001$ \\
\hline \multicolumn{14}{|l|}{ Payment (\%) } \\
\hline Medicare & 56.6 & 55.6 & 56.5 & 53.7 & 53.8 & 55.0 & 52.2 & 52.2 & 51.0 & 50.4 & 53.1 & 53.6 & $<0.0001$ \\
\hline Medicaid & 8.0 & 7.4 & 8.1 & 8.5 & 9.2 & 10.1 & 11.4 & 9.3 & 10.0 & 13.1 & 10.9 & 9.7 & $<0.0001$ \\
\hline Private insurance & 29.6 & 30.0 & 29.4 & 31.3 & 29.6 & 27.1 & 29.6 & 32.4 & 31.4 & 28.9 & 29.4 & 29.9 & 0.1379 \\
\hline Others (includes self-pay) & 5.7 & 7.0 & 5.9 & 6.5 & 7.3 & 7.6 & 6.7 & 6.0 & 7.4 & 7.3 & 6.4 & 6.7 & $<0.0001$ \\
\hline In-hospital mortality (\%) & 11.2 & 10.0 & 11.0 & 10.5 & 9.4 & 9.8 & 8.3 & 7.7 & 7.5 & 6.5 & 6.5 & 8.9 & $<0.0001$ \\
\hline Cost of care $(\$)$ & 21,710 & 22,547 & 24,414 & 21,757 & 24,243 & 23,737 & 26,190 & 24,761 & 23,361 & 26,296 & 24,706 & 23,975 & $<0.0001$ \\
\hline
\end{tabular}

Table 1 (continued) 
Table 1 (continued)

\begin{tabular}{|c|c|c|c|c|c|c|c|c|c|c|c|c|c|}
\hline Variable & 2001 & 2002 & 2003 & 2004 & 2005 & 2006 & 2007 & 2008 & 2009 & 2010 & 2011 & Overall & $P$ value \\
\hline $\begin{array}{l}\text { Acquired immunodeficiency } \\
\text { syndrome }\end{array}$ & 0.0 & 0.1 & 0.1 & 0.2 & 0.2 & 0.2 & 0.2 & 0.1 & 0.2 & 0.1 & 0.2 & 0.1 & 0.1338 \\
\hline Alcohol abuse & 0.0 & 2.5 & 2.2 & 2.6 & 2.7 & 3.0 & 2.5 & 3.1 & 2.9 & 3.5 & 3.9 & 2.6 & $<0.0001$ \\
\hline Deficiency anemias & 0.0 & 18.8 & 20.9 & 23.2 & 25.0 & 25.8 & 26.0 & 30.4 & 30.2 & 30.7 & 30.7 & 23.8 & $<0.0001$ \\
\hline Chronic blood loss anemia & 0.0 & 9.9 & 9.2 & 10.6 & 9.9 & 10.5 & 9.3 & 8.9 & 7.7 & 7.7 & 7.1 & 8.3 & $<0.0001$ \\
\hline Congestive heart failure & 0.0 & 7.4 & 7.2 & 7.8 & 7.8 & 7.7 & 6.8 & 7.5 & 6.2 & 6.6 & 7.3 & 6.6 & $<0.0001$ \\
\hline Chronic pulmonary disease & 0.0 & 14.0 & 14.0 & 15.9 & 15.7 & 16.5 & 15.0 & 15.0 & 14.3 & 14.3 & 15.7 & 13.7 & $<0.0001$ \\
\hline Coagulopathy & 0.0 & 2.7 & 3.2 & 3.3 & 3.6 & 3.7 & 4.0 & 4.5 & 5.5 & 5.6 & 6.3 & 3.9 & 0.0198 \\
\hline Drug abuse & 0.0 & 0.6 & 0.4 & 0.5 & 0.7 & 0.7 & 0.9 & 0.8 & 1.3 & 1.1 & 1.0 & 0.7 & $<0.0001$ \\
\hline Hypertension & 0.0 & 33.0 & 36.7 & 38.9 & 40.5 & 44.1 & 45.4 & 50.2 & 50.1 & 50.1 & 54.8 & 40.3 & $<0.0001$ \\
\hline Hypothyroidism & 0.0 & 4.9 & 5.2 & 5.5 & 5.9 & 5.6 & 6.7 & 7.8 & 7.5 & 8.1 & 8.6 & 6.0 & $<0.0001$ \\
\hline Liver disease & 0.0 & 1.9 & 2.1 & 1.9 & 2.4 & 3.0 & 2.7 & 3.0 & 3.4 & 3.5 & 3.7 & 2.5 & $<0.0001$ \\
\hline Lymphoma & 0.0 & 1.1 & 0.5 & 0.8 & 0.6 & 0.5 & 0.7 & 0.6 & 0.7 & 0.5 & 0.7 & 0.6 & $<0.0001$ \\
\hline $\begin{array}{l}\text { Fluid and electrolyte } \\
\text { disorders }\end{array}$ & 0.0 & 24.7 & 24.7 & 27.7 & 29.5 & 30.2 & 29.6 & 29.7 & 30.8 & 32.2 & 34.5 & 26.7 & $<0.0001$ \\
\hline Psychiatric disorder ${ }^{c}$ & 0.0 & 1.4 & 0.9 & 1.7 & 1.6 & 1.5 & 1.8 & 1.9 & 1.8 & 2.2 & 2.7 & 1.6 & $<0.0001$ \\
\hline $\begin{array}{l}\text { Pulmonary circulation } \\
\text { disorders }\end{array}$ & 0.0 & 0.6 & 0.5 & 0.3 & 0.6 & 0.5 & 2.3 & 2.8 & 3.0 & 3.3 & 3.3 & 1.6 & $<0.0001$ \\
\hline Renal failure & 0.0 & 2.0 & 2.3 & 2.8 & 3.5 & 5.2 & 5.9 & 6.6 & 6.4 & 6.7 & 8.9 & 4.6 & $<0.0001$ \\
\hline $\begin{array}{l}\text { Solid tumor without } \\
\text { metastasis }\end{array}$ & 0.0 & 2.8 & 1.1 & 0.6 & 1.1 & 1.0 & 1.1 & 0.9 & 1.5 & 1.4 & 1.2 & 1.1 & $<0.0001$ \\
\hline $\begin{array}{l}\text { Peptic ulcer disease } \\
\text { excluding bleeding }\end{array}$ & 0.0 & 4.1 & 0.5 & 0.7 & 0.7 & 0.8 & 0.8 & 0.8 & 0.7 & 0.7 & 0.5 & 1.0 & $<0.0001$ \\
\hline Valvular disease & 0.0 & 3.8 & 3.7 & 3.8 & 4.0 & 4.3 & 3.7 & 4.0 & 3.9 & 3.9 & 3.9 & 3.6 & 0.2845 \\
\hline Weight loss & 0.0 & 8.4 & 10.0 & 12.1 & 13.1 & 14.1 & 15.3 & 19.3 & 21.4 & 23.3 & 26.5 & 14.8 & $<0.0001$ \\
\hline
\end{tabular}

${ }^{a}$, rheumatic disorders include rheumatoid arthritis and other collagen vascular disorders; ${ }^{b}$, neurological disorders include hemiplegia, paralysis, and others; ' , psychiatric disorders include depression, psychosis, and others. AHRQ, Agency for Healthcare Research and Quality. Of note, data related to comorbidity measures were available only from 2002 to 2010. 


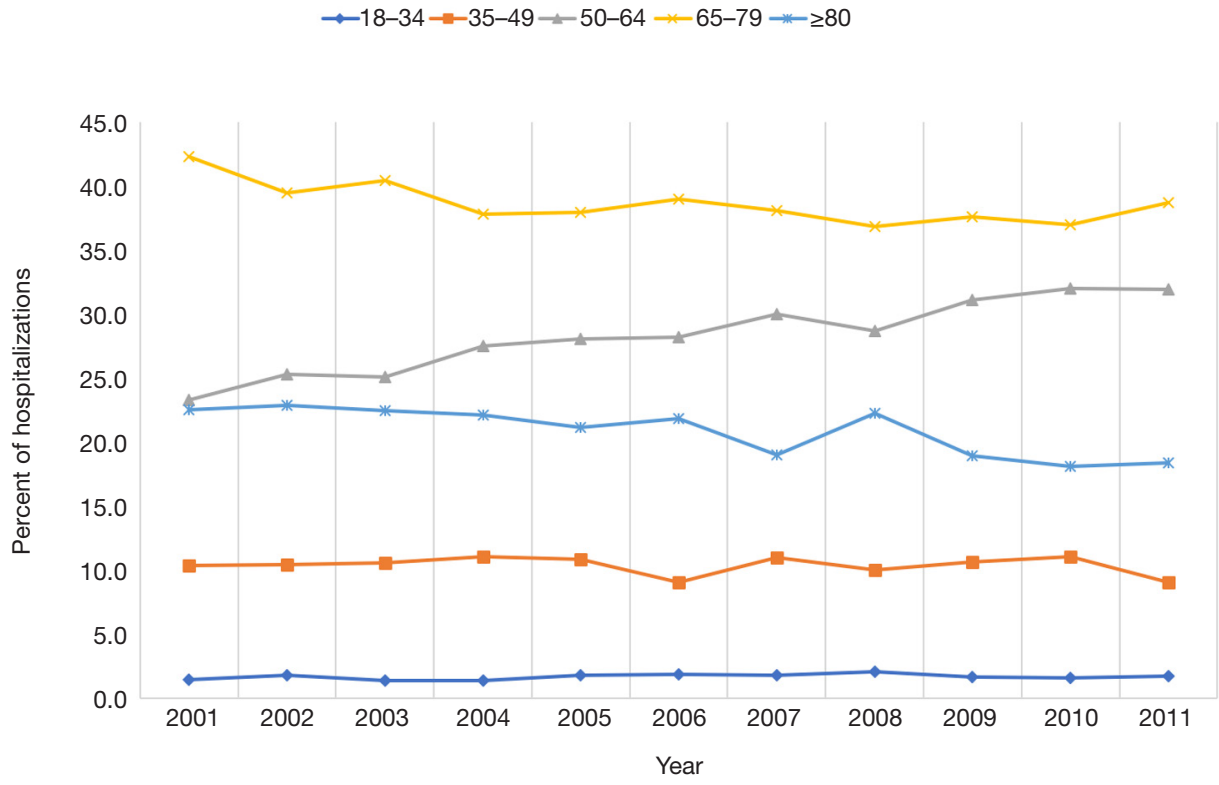

Figure 1 Age-wise distribution of gastric cancer hospitalizations.

Cancer Statistics (USCS), and National Center for Health Statistics (NCHS) (5,21-23).

Worldwide, gastric cancer ranked fifth [2015] for cancer incidence and was the third leading cause of cancer-related mortality worldwide $(24,25)$. It is the second most common cancer in East Asia and accounts for around 50\% of all new cases of gastric cancer worldwide. Globally, gastric cancer incidence has decreased steadily over the last 20 years decades. The reasons for downward trends in incidence are not definitively known. However, food refrigeration, falling rates of Helicobacter pylori (H. pylori) infection, screening programs, and decreased use of salted and smoked foods may be contributory $(26,27)$. In the U.S., reductions among Asian Americans have paralleled that observed in native countries (28).

In the U.S., gastric cancer is now relatively rare, ranking fifteenth among all of cancer diagnoses (29). Highest rates have been among native Koreans with lowest rates among non-Hispanic whites and Filipino Americans. In 2017, there were 28,000 estimated new cancer cases with 10,960 estimated deaths (22). From 2010 to 2014, the incidence rate was reported as 6.5 per 100,000 population. We found an incidence rate of 60.3 per 100,000 hospitalizations in our study, which was higher as we measured only the inpatient incidence rate (Table 2).

The incidence of gastric cancer is decreasing in most countries including the U.S. (30) However, the total number of gastric cancer-related hospitalizations remained stable throughout our study period and did not show a decline. This is likely due to the relatively short time frame (11 years) of our study or re-hospitalizations, perhaps for chemotherapy or palliative care. Early diagnosis, increase in the percent of patients receiving chemotherapy, and improved survival are the factors likely related to increased cost of care in gastric cancer patients as seen in other gastrointestinal cancers like esophageal and pancreatic cancers $(31,32)$.

Of the gastric cancer cases diagnosed between 2010 and 2014 in the U.S., approximately only $1.7 \%$ occurred between the ages of 20 and 34 years, whereas $22.9 \%$ occurred between 75 and 84 years. The highest incidence was reported between 65 and 74 years with a rate of $25.7 \%$ (22). The average age of diagnosis is 69 years and men are at higher risk than women (5). Our findings in the hospitalized group were comparable with highest incidence rates (24\%) among those 65 to 79 years of age (Table 1).

Siegel et al. reported estimated an incidence rate of stomach cancer from 2009 to 2013 at 4.6 and 9.2 for female and males per 100,000 population, respectively (21). It was reported to be 1.7 for female and 7.3 for males per 100,000 population 2010 to 2014 in another study (33). Our findings for inpatient admissions were similar (Table 1).

While we found higher incidence rates for inpatient gastric cancer hospitalization for whites compared to 
Table 2 Gastric cancer hospitalizations (\%) per 100,000 hospitalizations

\begin{tabular}{|c|c|c|c|c|c|c|c|c|c|c|c|c|}
\hline Variable & 2001 & 2002 & 2003 & 2004 & 2005 & 2006 & 2007 & 2008 & 2009 & 2010 & 2011 & Average \\
\hline \multicolumn{13}{|l|}{ Age in years } \\
\hline $18-34$ & 0.9 & 1.2 & 0.9 & 0.9 & 1.2 & 1.1 & 1.2 & 1.3 & 1.0 & 1.1 & 1.1 & 1.1 \\
\hline $35-49$ & 6.7 & 6.6 & 6.9 & 6.8 & 6.9 & 5.2 & 7.1 & 6.1 & 6.2 & 7.2 & 5.5 & 6.5 \\
\hline $65-79$ & 27.2 & 25.0 & 26.4 & 23.1 & 23.9 & 22.2 & 24.4 & 22.6 & 21.7 & 24.0 & 23.3 & 24.0 \\
\hline$\geq 80$ & 14.5 & 14.5 & 14.7 & 13.5 & 13.3 & 12.4 & 12.2 & 13.6 & 10.9 & 11.8 & 11.1 & 13.0 \\
\hline \multicolumn{13}{|l|}{ Gender } \\
\hline Male & 39.3 & 39.3 & 40.7 & 38.1 & 39.8 & 34.9 & 40.8 & 39.2 & 36.2 & 41.5 & 38.0 & 38.9 \\
\hline White & 32.2 & 29.8 & 31.4 & 29.3 & 29.8 & 25.3 & 29.6 & 31.9 & 28.4 & 33.2 & 33.8 & 30.4 \\
\hline Black & 6.7 & 6.7 & 7.3 & 7.4 & 5.8 & 6.1 & 7.2 & 7.6 & 6.7 & 10.0 & 9.0 & 7.3 \\
\hline Hispanic & 5.7 & 5.4 & 7.1 & 6.4 & 6.9 & 6.5 & 6.9 & 6.0 & 6.8 & 9.6 & 8.1 & 6.9 \\
\hline Asian or Pacific Islander & 2.6 & 3.9 & 3.8 & 3.3 & 3.5 & 3.2 & 4.4 & 3.9 & 4.4 & 3.8 & 3.2 & 3.6 \\
\hline Native American & 0.1 & 0.2 & 0.1 & 0.2 & 0.1 & 0.2 & 0.5 & 0.2 & 0.3 & 0.6 & 0.2 & 0.2 \\
\hline Others & 1.3 & 1.5 & 1.5 & 1.0 & 1.6 & 1.3 & 1.7 & 1.7 & 2.3 & 2.2 & 2.3 & 1.7 \\
\hline \multicolumn{13}{|l|}{ Region } \\
\hline Northeast & 16.7 & 15.1 & 15.2 & 16.2 & 15.7 & 12.7 & 18.4 & 14.8 & 12.6 & 15.9 & 13.6 & 15.2 \\
\hline Urban nonteaching & 26.0 & 24.7 & 25.6 & 25.4 & 26.4 & 20.3 & 20.5 & 22.2 & 19.8 & 19.9 & 20.4 & 22.8 \\
\hline Urban teaching & 3.2 & 3.2 & 3.3 & 3.0 & 3.2 & 3.2 & 3.9 & 3.5 & 3.3 & 4.0 & 3.6 & 3.4 \\
\hline \multicolumn{13}{|l|}{ Median household income } \\
\hline Quartile 1 & 4.1 & 2.6 & 16.6 & 16.6 & 15.9 & 15.3 & 17.0 & 16.3 & 14.9 & 18.2 & 16.1 & 14.0 \\
\hline Quartile 2 & 13.1 & 12.7 & 17.2 & 15.9 & 15.1 & 13.6 & 14.7 & 15.1 & 14.0 & 15.5 & 14.2 & 14.6 \\
\hline Quartile 3 & 17.6 & 14.3 & 16.1 & 12.8 & 16.3 & 13.8 & 14.5 & 13.8 & 13.3 & 14.7 & 14.8 & 14.7 \\
\hline Quartile 4 & 28.8 & 32.3 & 14.1 & 14.3 & 14.3 & 13.0 & 16.2 & 14.4 & 13.5 & 14.6 & 14.4 & 17.3 \\
\hline \multicolumn{13}{|l|}{ Payment } \\
\hline Medicare & 36.3 & 35.2 & 36.9 & 32.8 & 33.9 & 31.3 & 33.5 & 31.9 & 29.5 & 32.7 & 32.0 & 33.3 \\
\hline Medicaid & 5.1 & 4.7 & 5.3 & 5.2 & 5.8 & 5.8 & 7.3 & 5.7 & 5.8 & 8.5 & 6.6 & 6.0 \\
\hline Private insurance & 19.0 & 19.0 & 19.2 & 19.1 & 18.7 & 15.4 & 19.0 & 19.8 & 18.1 & 18.7 & 17.7 & 18.5 \\
\hline Others (includes self-pay) & 3.6 & 4.4 & 3.8 & 3.9 & 4.6 & 4.3 & 4.3 & 3.7 & 4.3 & 4.7 & 3.9 & 4.1 \\
\hline
\end{tabular}


Table 3 All-cause in-hospital mortality (\%) for gastric cancer hospitalizations

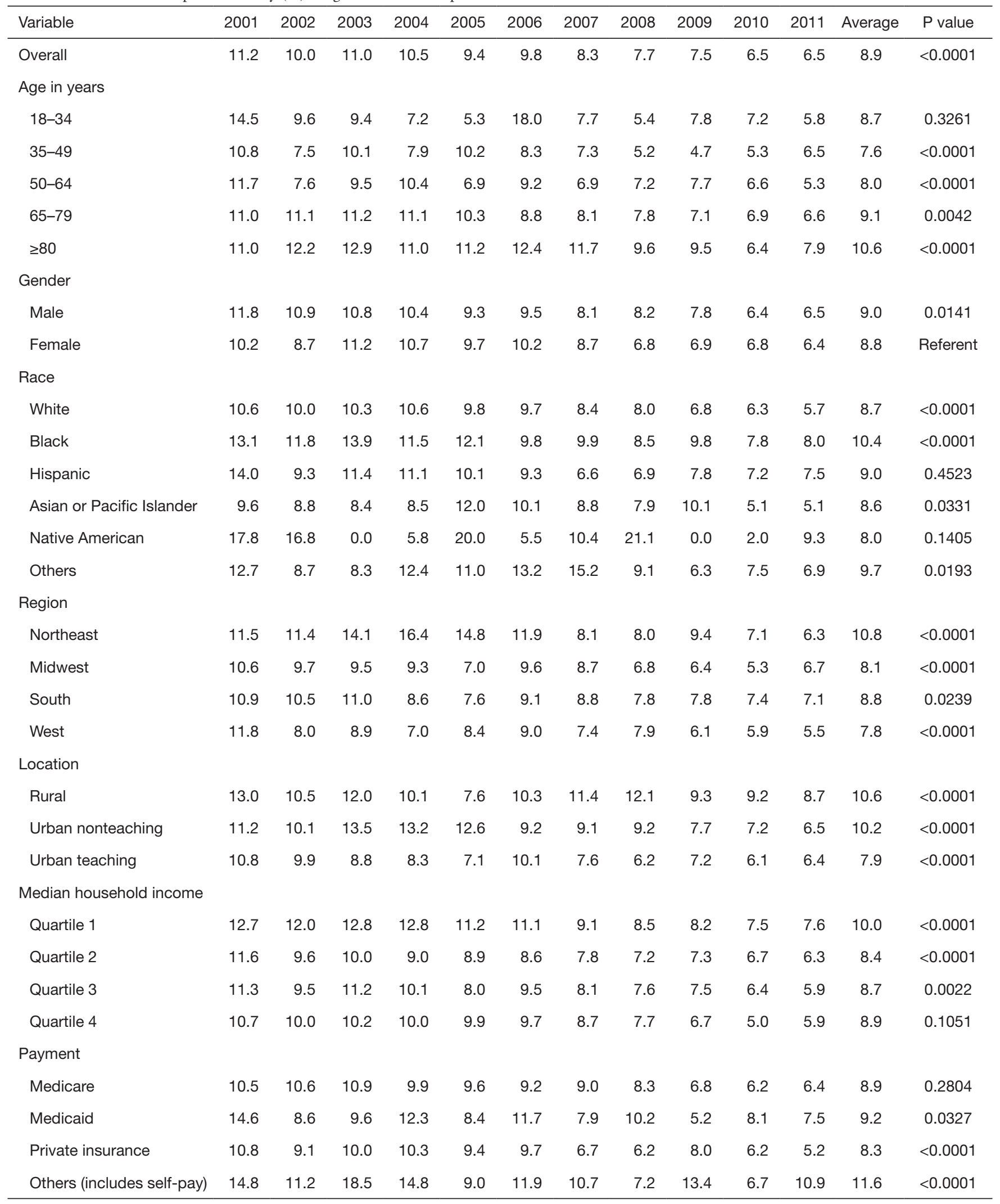




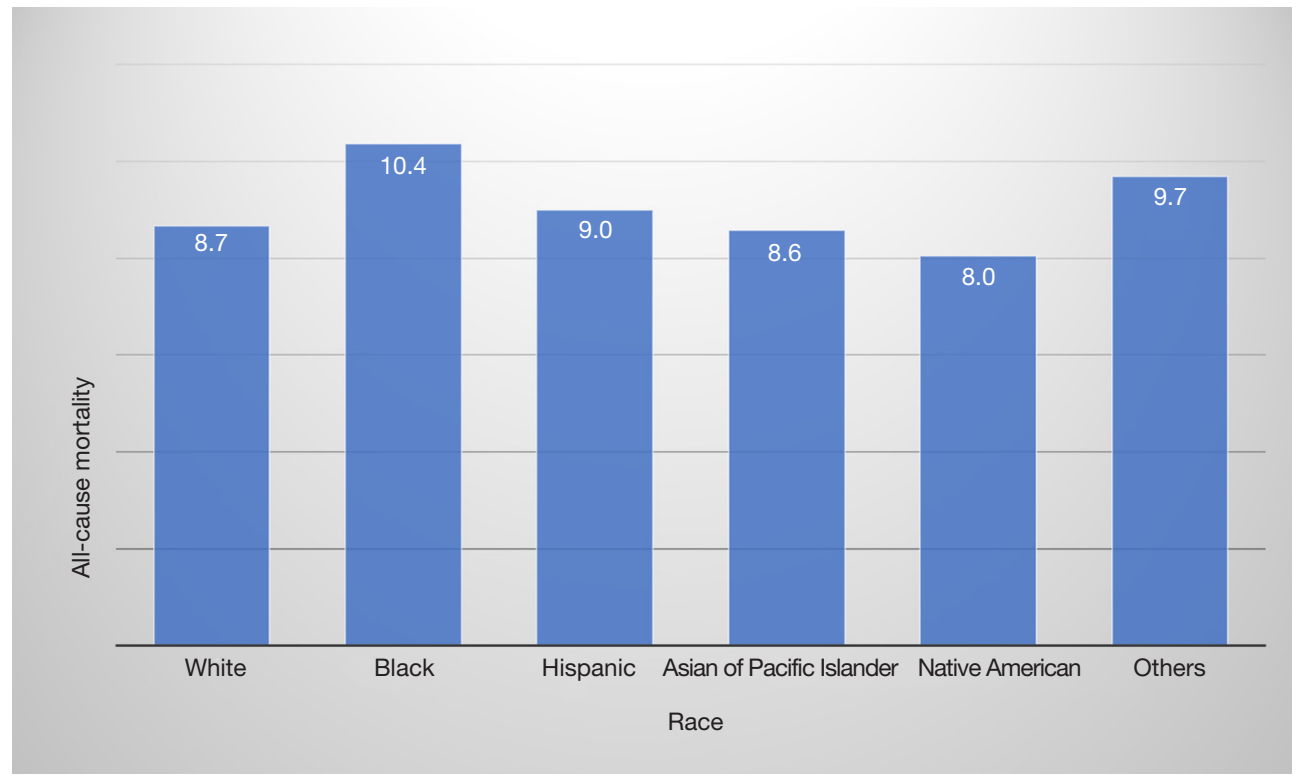

Figure 2 Racial differences in all-cause mortality.

other racial groups, it is important to recognize that rates of hospital admission are not necessarily reflective of the incidence in the population at large. As such our findings are not necessarily inconsistent with earlier studies which have found that the incidence of gastric cancer in the White (non-Hispanic) population was lower (8.2 cases per 100,000 person-years) than values for Asians, Hispanics, and non-Hispanic black persons (respectively: 12.7, 12.7, and 11.8 cases per 100,000 person-years) (34). However, the number of gastric cancer hospitalizations was higher in the White population than any other racial group in our study. This difference is likely due to poor health insurance coverage amongst the non-White races. Kirby and Kaneda reported that Blacks are twice as likely to be uninsured as compared to Whites and Hispanics are thrice as likely (35). In addition, our in-patient results are consistent with earlier studies that mortality is higher in the Black population in the U.S. than the White population $(23,36,37)$.

Our analysis demonstrates that Medicare and Medicaid paid for the highest number of hospitalizations $(63.3 \%)$ in the U.S. during our study period. Private insurance paid for only $29.4 \%$ of the hospitalizations. Together, Medicare and Medicaid represent $39 \%$ of national health spending in the U.S (38). One of the highest uninsured rates was seen in patients with stomach cancer $(9.7 \%)$ by Grant $e t$ al. between 2007 and 2010 in the U.S. population (39). We postulate that providing these patients with Medicare/Medicaid coverage will further reduce the mortality associated with gastric cancer hospitalizations in the U.S. A Korean study showed that private health insurance only maintains the financial independence of its beneficiaries but does not improve cancer care in patients with gastric cancer (40). Under Japanese national health scheme implemented by the government, the incidence of peptic ulcer decreased dramatically by about $60 \%$ over 10 years which in turn is projected to decrease gastric cancer incidence and deaths in Japan in the upcoming decades (41). Such programs can reduce gastric cancer incidence in developing and underdeveloped nations. Also, the model of universal healthcare coverage implemented in the U.S. can be applied in other countries for better coverage of uninsured populations affected by gastric cancer, thus reducing out-ofpocket costs for such populations and reducing the overall all-cause mortality.

Obesity has been associated with elevated cancer risk $(42,43)$. Our analysis also showed a significant association of obesity with risk of mortality in gastric cancer patients (OR 2.0; 95\% CI: 1.6 to 2.6; $\mathrm{P}<0.0001$ ) (Table 5). In 2014, a Chinese study with 8,820 participating subjects showed that obesity was significantly and positively associated with $\mathrm{H}$. pylori infection in the Chinese population (44). In 2017, another Chinese study done on 3,039 participants concluded that obesity had no association with H. pylori infection (45). Thus, the association between obesity and $\mathrm{H}$. pylori infection is still unclear. It will be interesting to see if future studies can demonstrate a significant association 


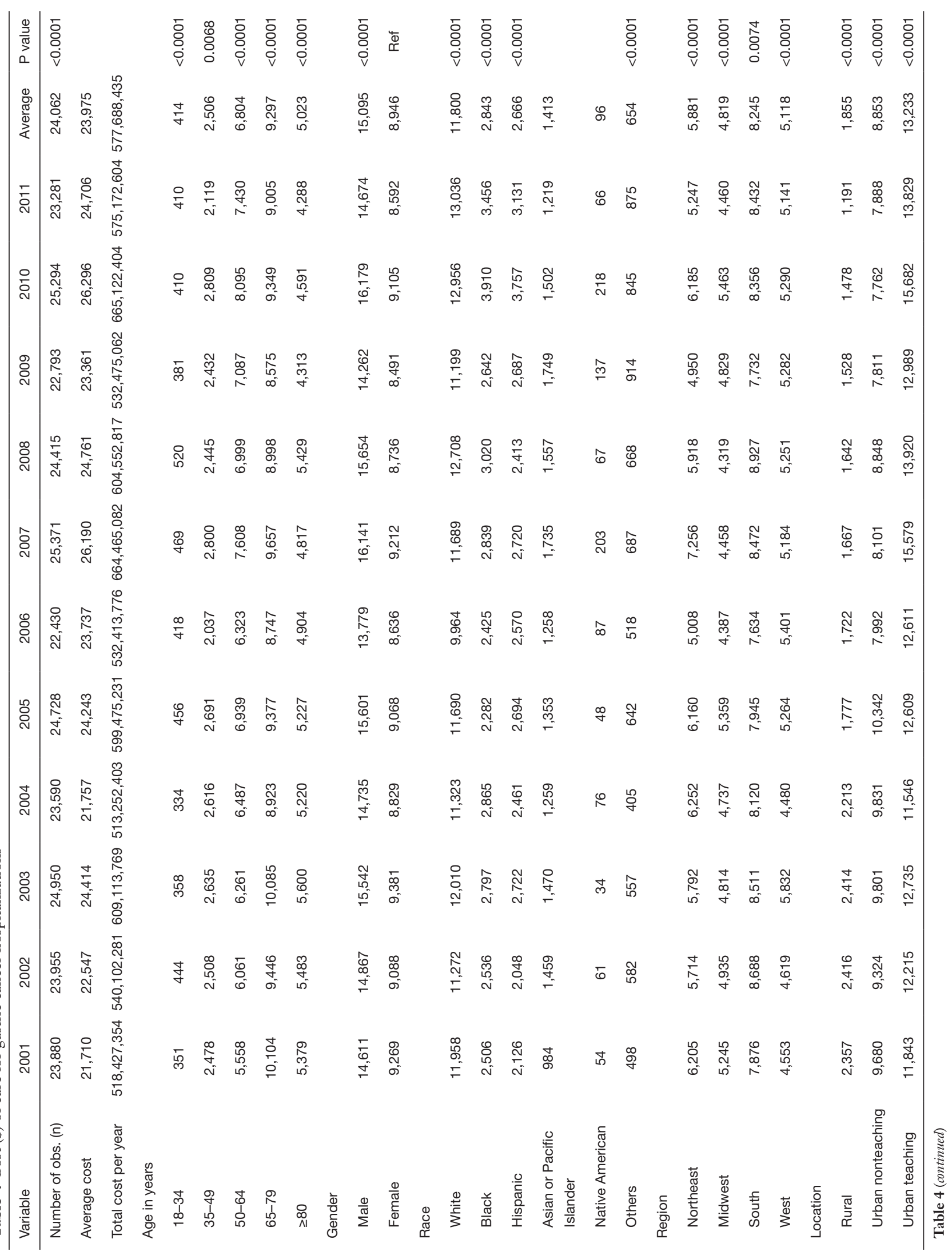




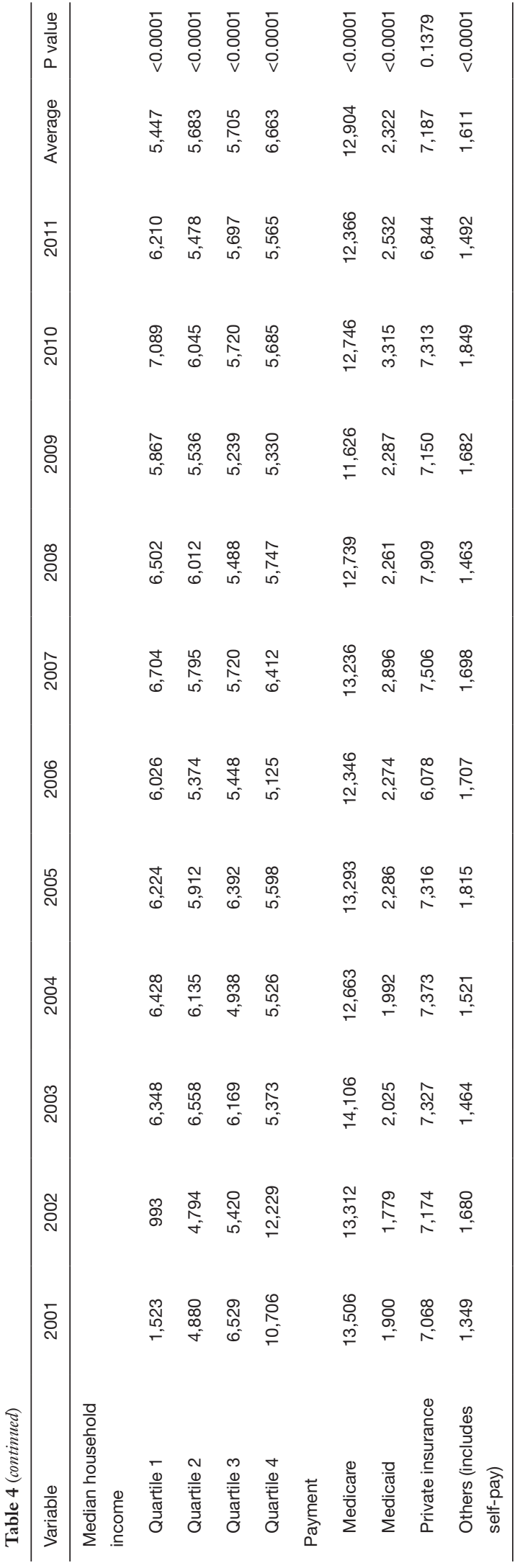

between obesity and H. pylori infection in the U.S. population.

Previous studies have reported age-standardized cancer mortality rates in gastric cancer (46). Siegel et al. reported that mortality rate was 2.4 per 100,000 population for females and 4.5 per 100,000 population for males from 2009 to 2013 (21). We found a mortality rate of 2.0 per 100,000 hospitalizations for females and 3.5 per 100,000 hospitalizations for males. In Japan, 5-year (5-YSR) survival rates have been noted to be $69.1 \%$ for patients with primary gastric cancer (47). However, the 5-YSR in the U.S. was only $30.6 \%$ from 2007 to 2013 (21). Higher survival rates in Japan may be due to effectiveness of mass screening programs leading to early diagnosis $(48,49)$. This led Kim et al. to propose multicenter studies to evaluate the effectiveness of gastric cancer screening programs in highrisk individuals (50).

Our literature review did not reveal any studies focusing on the use of endoscopy for gastric cancer screening in the U.S. during the last decade. Also, the guidelines for gastric cancer screening and gastric intestinal metaplasia surveillance are lacking in the U.S. (50). Thus, it is unclear if surveillance and early detection contributed to the decline in mortality rate demonstrated by our study. Nationwide studies designed to determine endoscopy utilization rates in gastric cancer diagnosis are needed to support our findings.

In our study, the average cost of care from 2001 to 2011 was $\$ 23,975$. In 2009 , it was found to be $\$ 23,361$. Statistical brief \#125 provided by AHRQ in 2009 estimated the mean hospital cost for gastric cancer as $\$ 22,200$ (51). Thus, our estimates for average cost of care for inpatient gastric cancer hospitalization closely reflect AHRQ's cost estimates.

The strength of this study is that analysis of the NIS database permitted us to study a large population, which reduces bias seen in studies that are confined to a single region or hospital. However, our analysis had a number of significant limitations. Administrative databases are susceptible to errors arising from coding inaccuracies. The gastric cancer diagnosis and the presence of comorbidities were based on the presence of administrative codes. ICD$9 \mathrm{CM}$ codes 151.x is validated for gastric cancer in the administrative database. The database did not permit us to determine which patients assigned a code of "gastric cancer" were hospitalized for the new diagnosis, as opposed to patients who had a diagnosis of gastric cancer in the past.

There is a risk that our analysis could underestimate the number of gastric cancer hospitalizations each year. If a gastric cancer diagnosis accompanied other "serious" 
Table 5 Predictors of mortality for gastric cancer hospitalizations

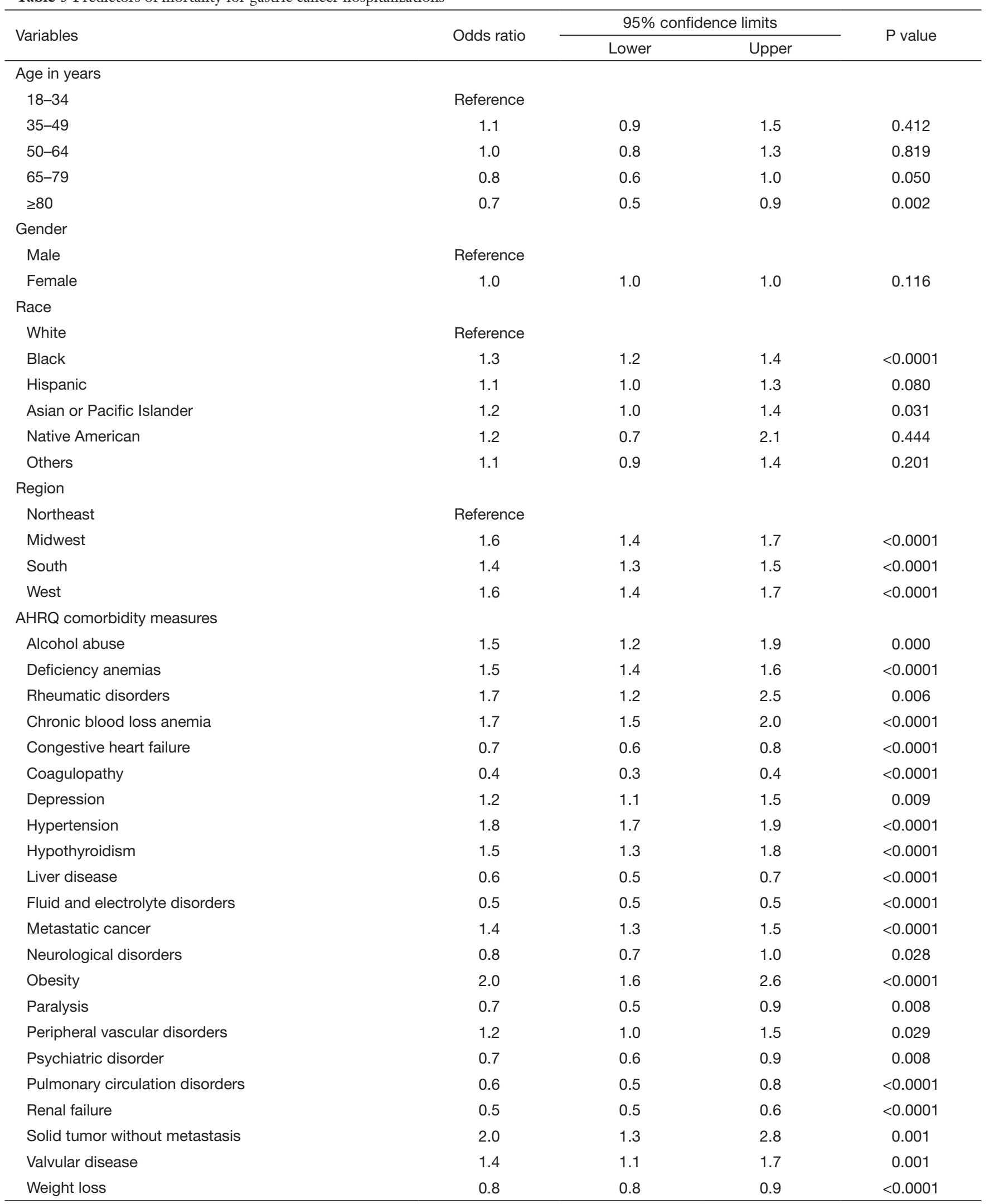


conditions-e.g., "gastric perforation"-the latter might be listed as a primary diagnosis, even if a patient's primary diagnosis was gastric cancer.

Our analysis could also overestimate the number of patients with gastric cancer. In fact, the NIS considers each hospitalization as separate entry. Thus, there is no coding method that can separate index cases from readmissions. Further, the design of the database allowed us to examine in-hospital characteristics only and does not permit analysis of long-term follow-up outcomes or health care utilization in out-patient settings or emergency departments.

In conclusion, our review of hospitalization trends over the last decade showed that the number of gastric cancerrelated hospitalizations remained stable. There was an increase in the cost of care, but with a substantial reduction in mortality rates over the last decade. It is possible that improved out-patient care and enhanced use of gastric cancer screening may reduce the number of hospitalizations with gastric cancer in the future.

\section{Acknowledgments}

None.

\section{Footnote}

Conflicts of Interest: Presented at: Digestive Disease Week. Walter E. Washington Convention Center, Washington, DC. May 2018.

Ethical Statement: The authors are accountable for all aspects of the work in ensuring that questions related to the accuracy or integrity of any part of the work are appropriately investigated and resolved. This study was exempted from ethics approval because we did not use personally identifiable information (PII).

\section{References}

1. Crew KD, Neugut AI. Epidemiology of gastric cancer. World J Gastroenterol 2006;12:354-62.

2. Wingo PA, Cardinez CJ, Landis SH, et al. Long-term trends in cancer mortality in the United States, 1930-1998. Cancer 2003;97:3133-275.

3. Ferro A, Peleteiro B, Malvezzi M, et al. Worldwide trends in gastric cancer mortality (1980-2011), with predictions to 2015 , and incidence by subtype. Eur J Cancer 2014;50:1330-44.
4. Hundahl SA, Phillips JL, Menck HR. The National Cancer Data Base Report on poor survival of U.S. gastric carcinoma patients treated with gastrectomy: Fifth Edition American Joint Committee on Cancer staging, proximal disease, and the "different disease" hypothesis. Cancer 2000;88:921-32.

5. National Cancer Institute. SEER Stat Fact Sheets: Stomach Cancer. 2017. Available online: https://seer. cancer.gov/statfacts/html/stomach.html. Accessed January 82018.

6. Dicken BJ, Bigam DL, Cass C, et al. Gastric adenocarcinoma: review and considerations for future directions. Ann Surg 2005;241:27-39.

7. Mariotto AB, Yabroff KR, Shao Y, et al. Projections of the cost of cancer care in the United States: 2010-2020. J Natl Cancer Inst 2011;103:117-28.

8. Knopf KB, Smith DB, Doan JF, et al. Estimating the economic burden of gastric cancer in the United States. J Clin Oncol 2011;29:e16589.

9. Pharma Evidence. IMS LifeLink Health Plan Claims Database. 2018. Available online: https://www. pharmaevidence.com/ep/ims-lifelink-health-plan-claimsdatabase/. Accessed February 192018.

10. Shi L, Stevens GD. Vulnerability and unmet health care needs. The influence of multiple risk factors. J Gen Intern Med 2005;20:148-54.

11. Patel NJ, Deshmukh A, Pant S, et al. Contemporary trends of hospitalization for atrial fibrillation in the United States, 2000 through 2010: implications for healthcare planning. Circulation 2014;129:2371-9.

12. Healthcare Cost and Utilization Project. Overview of the National (Nationwide) Inpatient Sample (NIS). Available online: https://www.hcup-us.ahrq.gov/nisoverview.jsp. Accessed January 172018.

13. HCUP Elixhauser Comorbidity Software. Healthcare Cost and Utilization Project (HCUP) [database on the Internet]. June 2017. Available online: www.hcup-us.ahrq. gov/toolssoftware/comorbidity/comorbidity.jsp. Accessed: July 2017.

14. Badheka AO, Chothani A, Mehta K, et al. Utilization and adverse outcomes of percutaneous left atrial appendage closure for stroke prevention in atrial fibrillation in the United States: influence of hospital volume. Circ Arrhythm Electrophysiol 2015;8:42-8.

15. Healthcare Cost and Utilization Project. NIS Related Reports. Available online: https://www.hcup-us.ahrq. gov/db/nation/nis/nisrelatedreports.jsp. Accessed January 172018. 
16. Singh V, Rodriguez AP, Thakkar B, et al. Hospital Admissions for Chest Pain Associated with Cocaine Use in the United States. Am J Med 2017;130:688-98.

17. Healthcare Cost and Utilization Project. HCUP Methods Series. Available online: https:/www.hcup-us.ahrq.gov/ reports/methods/1998ChangesintheNISRedesignFinal. pdf. Accessed January 172018.

18. Armitage P. Tests for Linear Trends in Proportions and Frequencies. Biometrics 1955;11:375-86.

19. Nahm FS. Nonparametric statistical tests for the continuous data: the basic concept and the practical use. Korean J Anesthesiol 2016;69:8-14.

20. Liu D, Mehta D, Kaur S, et al. Decreasing mortality and hospitalizations with rising costs related to gastric cancer in the USA: an epidemiological perspective. J Hematol Oncol 2018;11:138.

21. Siegel RL, Miller KD, Jemal A. Cancer Statistics, 2017. CA Cancer J Clin 2017;67:7-30.

22. National Cancer Institute. SEER Cancer Statistics Review (CSR) 1975-2014. 2017. Available online: https://seer. cancer.gov/csr/1975_2014/. Accessed January 82018.

23. Singh GK, Jemal A. Socioeconomic and Racial/Ethnic Disparities in Cancer Mortality, Incidence, and Survival in the United States, 1950-2014: Over Six Decades of Changing Patterns and Widening Inequalities. J Environ Public Health 2017;2017:2819372.

24. Fitzmaurice C, Allen C, Barber RM, et al. Global, Regional, and National Cancer Incidence, Mortality, Years of Life Lost, Years Lived With Disability, and DisabilityAdjusted Life-years for 32 Cancer Groups, 1990 to 2015: A Systematic Analysis for the Global Burden of Disease Study. JAMA Oncol 2017;3:524-48.

25. Marques-Lespier JM, Gonzalez-Pons M, Cruz-Correa M. Current Perspectives on Gastric Cancer. Gastroenterol Clin North Am 2016;45:413-28.

26. Ford AC, Forman D, Hunt R, et al. Helicobacter pylori eradication for the prevention of gastric neoplasia. Cochrane Database Syst Rev 2015;(7):CD005583.

27. Fuccio L, Zagari RM, Eusebi LH, et al. Meta-analysis: can Helicobacter pylori eradication treatment reduce the risk for gastric cancer? Ann Intern Med 2009;151:121-8.

28. Kamineni A, Williams MA, Schwartz SM, et al. The incidence of gastric carcinoma in Asian migrants to the United States and their descendants. Cancer Causes Control 1999; 10:77-83.

29. American Cancer Society. Key Statistics for Stomach Cancer. 2018. Available online: https://www.cancer.org/ cancer/stomach-cancer/about/key-statistics.html\#written_ by. Accessed January 82018.

30. Rawla P, Barsouk A. Epidemiology of gastric cancer: global trends, risk factors and prevention. Prz Gastroenterol 2019;14:26-38.

31. Warren JL, Yabroff KR, Meekins A, et al. Evaluation of trends in the cost of initial cancer treatment. J Natl Cancer Inst 2008;100:888-97.

32. Ashtari S, Vahedi M. Economic burden of gastrointestinal cancer: estimation and importance. Translational Gastrointestinal Cancer 2014;3:178-81.

33. Ashktorab H, Kupfer SS, Brim H, et al. Racial Disparity in Gastrointestinal Cancer Risk. Gastroenterology 2017;153:910-23.

34. Dong E, Duan L, Wu BU. Racial and Ethnic Minorities at Increased Risk for Gastric Cancer in a Regional US Population Study. Clin Gastroenterol Hepatol 2017;15:511-7.

35. Kirby JB, Kaneda T. Unhealthy and uninsured: exploring racial differences in health and health insurance coverage using a life table approach. Demography 2010;47:1035-51.

36. Merchant SJ, Li L, Kim J. Racial and ethnic disparities in gastric cancer outcomes: more important than surgical technique? World J Gastroenterol 2014;20:11546-51.

37. DeSantis CE, Siegel RL, Sauer AG, et al. Cancer statistics for African Americans, 2016: Progress and opportunities in reducing racial disparities. CA Cancer J Clin 2016;66:290-308.

38. Altman D, Frist WH. Medicare and Medicaid at 50 Years: Perspectives of Beneficiaries, Health Care Professionals and Institutions, and Policy Makers. JAMA 2015;314:384-95.

39. Grant SR, Walker GV, Guadagnolo BA, et al. Variation in insurance status by patient demographics and tumor site among nonelderly adult patients with cancer. Cancer 2015;121:2020-8.

40. Shin DW, Jung KT, Kim S, et al. Impact of supplementary private health insurance on stomach cancer care in Korea: a cross-sectional study. BMC Health Serv Res 2009;9:133.

41. Asaka M, Mabe K. Strategies for eliminating death from gastric cancer in Japan. Proc Jpn Acad Ser B Phys Biol Sci 2014;90:251-8.

42. Li Q, Zhang J, Zhou Y, et al. Obesity and gastric cancer. Front Biosci (Landmark Ed) 2012;17:2383-90.

43. Yang P, Zhou Y, Chen B, et al. Overweight, obesity and gastric cancer risk: results from a meta-analysis of cohort studies. Eur J Cancer 2009;45:2867-73.

44. Xu C, Yan M, Sun Y, et al. Prevalence of Helicobacter pylori infection and its relation with body mass index in a 
Chinese population. Helicobacter 2014;19:437-42.

45. Xu MY, Liu L, Yuan BS, et al. Association of obesity with Helicobacter pylori infection: A retrospective study. World J Gastroenterol 2017;23:2750-6.

46. Mokdad AH, Dwyer-Lindgren L, Fitzmaurice C, et al. Trends and Patterns of Disparities in Cancer Mortality Among US Counties, 1980-2014. JAMA 2017;317:388-406.

47. Isobe $\mathrm{Y}$, Nashimoto A, Akazawa K, et al. Gastric cancer treatment in Japan: 2008 annual report of the JGCA nationwide registry. Gastric Cancer 2011;14:301-16.

48. Bollschweiler E, Boettcher K, Hoelscher AH, et al. Is the

Cite this article as: Solanki S, Chakinala RC, Haq KF, Khan MA, Kifayat A, Linder K, Khan Z, Mansuri U, Haq KS, Nabors $\mathrm{C}$, Aronow WS. Inpatient burden of gastric cancer in the United States. Ann Transl Med 2019;7(23):772. doi: 10.21037/ atm.2019.11.54 prognosis for Japanese and German patients with gastric cancer really different? Cancer 1993;71:2918-25.

49. Sugano K. Screening of gastric cancer in Asia. Best Pract Res Clin Gastroenterol 2015;29:895-905.

50. Kim GH, Liang PS, Bang SJ, et al. Screening and surveillance for gastric cancer in the United States: Is it needed? Gastrointest Endosc 2016;84:18-28.

51. Healthcare Cost and Utilization Project. Cancer Hospitalizations for Adults, 2009. Available online: https:// www.hcup-us.ahrq.gov/reports/statbriefs/sb125.jsp.

Accessed October 252019. 